\title{
Do you need a weatherman to know which way the wind blows?
}

\section{DOI: 10.7861/clinmed.ed.22.1.1}

The new year dawns for many clinicians with the familiar dichotomous feeling of good intentions for the year ahead but doubts about repeating past missteps. And the latest wave of the COVID pandemic only serves to accentuate that division, as the pressures of clinical work make it hard to plan beyond the end of the next shift. The role of a journal like Clin Med is especially relevant at times when physicians are often working beyond their specialty area in terms of keeping abreast of best practice. This edition therefore features several papers offering updated guidance for common inpatient scenarios - our intention is to be a handy weatherman, rather than detailed forecaster.

With the upsurge of COVID-19 related admissions, it is timely to publish a collaborative paper on how scores for community acquired pneumonia and sepsis perform as risk stratification tools in COVID-19 infected patients in the first wave of the pandemic.' It will not be a surprise that these tools proved ineffective in stratifying these patients, most likely because most were derived and validated in very different patient cohorts. As such it highlights the importance of developing appropriate tools, possibly including social determinants of health, to aid clinician decision making with COVID-19 admissions. That this study was produced by a trainee collaborative highlights another dimension of the clinician response to the challenges of the pandemic.

The difficulties in the acute care setting are matched by those faced in the follow up of patients and as we try to ensure the recovery of elective services. The article by Anstey et $a l^{2}$ describes a way of evaluating radiological recovery from COVID within a resource-constrained service. The authors describe how they adapted British Thoracic Society guidelines and developed a clinico-radiological multidisciplinary team to help assign postCOVID-19 admission care. The paper reports both patient outcomes and resource optimisation and will hopefully help other hospital teams plan follow-up needs effectively.

The Centre for Perioperative Care recently produced guidelines for peri-operative care of people with diabetes, who are known to have an increased risk of complications. Individually tailored pre-operative care and clear communication between specialist teams and the patient are the key focus. The summary of this guidance ${ }^{3}$ will be of great practical valuable to trainee doctors caring for these patients on the wards. Equally valuable to those trainee doctors who are revising is this month's CME section on tropical diseases - a read of these high-quality reviews will help in not having to 'skip' those questions in exams. There are also summaries of the NICE guideline on atrial fibrillation (specifically with regard to wearable technology $)^{4}$ and a state-of-the-art review for the non-specialist of the indications for kidney biopsy. ${ }^{5}$ We are also honoured to publish Sir Peter Ratcliffe's Harveian oration on how cells can sense and adapt to changing oxygen availability. Oxygen sensing is key to a number of pathophysiological processes, from immune dysfunction to chronic renal failure and cancer. ${ }^{6}$ The potential for drug development to activate or block the oxygen-sensing mechanisms, and thereby have an effect on a wide range of disorders is an exciting take-away from the lecture.

Moving forward, ClinMed is a key component of the emerging Royal College of Physicians research strategy, and we anticipate featuring the same diversity of content, with a strong focus on the practical, but strengthening the research domain. As the journal's impact factor climbs (now 2.659) we look forward to jointly developing our clinical research content.

Anton Emmanuel Editor-in-chief

\section{References}

1 Ahmed A, Alderazi SA, Aslam R et al. Utility of severity assessment tools in COVID-19 pneumonia: a multicentre observational study. Clin Med 2022;22:63-70.

2 Anstey R, Rossdale J, Dereham A et al. Screening success: A virtual MDT can reduce the number of patients requiring respiratory follow-up post-COVID-19 pneumonia in line with British Thoracic Society guidance. Clin Med 2022;22:45-50.

3 Grant B, Chowdhury TA. New guidance on the perioperative management of diabetes. Clin Med 2022;22:41-4.

4 Briosa e Gala, Pope MTB, Leo M et al. NICE atrial fibrillation guideline snubs wearable technology: a missed opportunity? Clin Med 2022;22:77-82.

5 Hull KL, Adenwalla SF, Topham P, Graham-Brown MP. Indications and considerations for kidney biopsy: an overview of clinical considerations for the non-specialist. Clin Med 2022;22:34-40.

6 Ratcliife P. Harveian Oration 2020: Elucidation of molecular oxygen sensing mechanisms in human cells: implications for medicine. Clin Med 2022;22:23-33.

$\begin{array}{ll}\text { Members of the editorial board } \\ \text { Cono Ariti } & \text { Anton Emmanuel } \\ \text { Ian Chan } & \text { Kate Evans } \\ \text { Tim Chevassut } & \text { William Gibson } \\ \text { Tahseen Chowdhury } & \text { Anna Goodman } \\ \text { Richard Corbett } & \text { Tevfik Ismail } \\ \text { Andrew Davies } & \text { Vikas Kapil } \\ \text { Elaine Dennison } & \text { Neelam Kumar } \\ \text { Arosha Dissanayake } & \text { Yash Mahida }\end{array}$

Martin McKee Andrew Medford Mehool Patel Gerrard Phillips Sushma Saksena Philip Smith Angela Star Cameron Swift
Rhys Thomas

Trainee associate editors: Tessa Cacciottolo Rajan Pooni Anenta Ramakrishnan

Trainee column editor: Adam Truelove 